\title{
Krukenberg tumor from gastric carcinoma as acute abdomen
}

\begin{abstract}
Aparna $\mathbf{J}^{1}$
\section{Introduction}

The Krukenberg tumor is a mysterious ovarian metastasis of a primary gastrointestinal tumor accounting for $1-2 \%$ of all ovarian tumors ${ }^{1}$. Commonly these tumors present as abdominal swelling and pain but very rarely as acute abdomen. We report an unusual case of bilateral Krukenberg tumor presented as acute abdomen due to unilateral ovarian torsion.
\end{abstract}

\section{Case report}

A 36 year old parous lady, presented to emergency department in the early hours of the morning with the complaints of left lower quadrant abdominal pain for few hours with increasing intensity, continuous, nonradiating, not associated with any history of vomiting or fever. She had no prior medical illnesses or gynaecological complaints.

Physical examination revealed a moderately built female with normal vitals. Cardiopulmonary, breast and thyroid examinations were unremarkable. On examination a tender mass of cystic to firm in consistency occupying the left lumbar, iliac extending into the pelvis and left hypochondriac region was found.

Pelvic examination revealed a mass lying in anterior, left lateral fornix and uterus could not be made out separately. An emergency abdominal ultrasonography showed a

\footnotetext{
${ }^{1}$ Assistant Professor, Department of Obstetrics and Gynaecology, The Shadan Institute of Medical Sciences, Himayatsagar Road, Hyderabad, Andhra Pradesh, India, 500008.

Correspondence: J Aparna

E-mail: draparnaj@gmail.com
}

cystic to solid mass with multiple septations in left lumbar region giving the impression as left ovarian mass $(14 \times 10 \times 8 \mathrm{~cm})$ with minimal free fluid in abdomen and left pleural effusion. On emergency laparotomy there was minimal hemoperitoneum. A cystic to solid mass with bosselated appearance with torsion of 2 turns of right ovary $(14 \times 10 \times 8 \mathrm{~cm})$ and hemorrhagic areas were found. Left ovary too was asymmetrically enlarged to the size of $9 \times 5 \times 3 \mathrm{~cm}$, variegated in appearance and consistency. Hence decided for frozen section, which was inconclusive, giving torsion related changes and tubular structures of columnar to cuboidal origin (Figure 1A). Intraoperatively surgical oncologist opinion was taken in view of suspicious frozen report. An infiltrative growth was felt in the greater curvature of the stomach. No peritoneal, omental deposits, serosal invasion were detected thus proceeded with total abdominal hysterectomy with bilateral salpingoovariotomy. Fluid cytology was negative for malignant cells. Tumor markers CA125 $(18.9 \mathrm{u} / \mathrm{ml})$, and CEA $(2.12 \mathrm{ng} / \mathrm{ml})$ were within normal limits. The final report described typical Krukenberg tumors with poorly differentiated signet ring adenocarcinoma (Figure 1B).

Upper G.I. endoscopy done after the final report showed ulceropro-

\section{Figure 1. Histological appearance.}
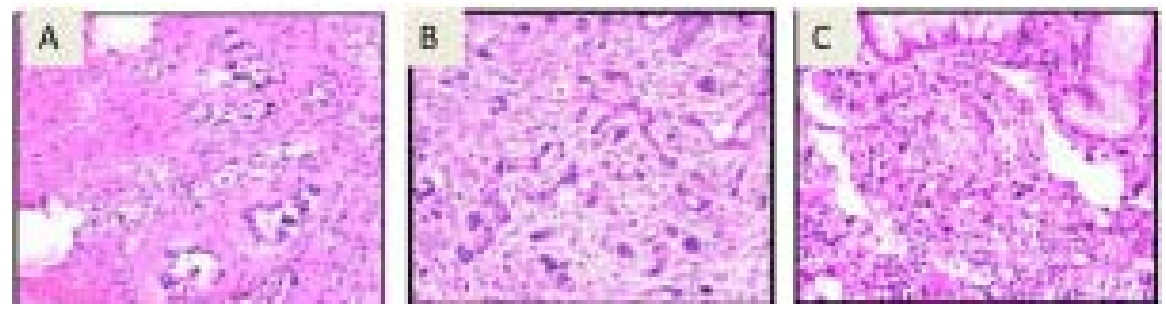

liferative growth in the greater curvature of the stomach for which biopsy was taken. Poorly differentiated adenocarcinoma with focal signet ring cell formation was the biopsy report and therefore planned for radical surgery. Subtotal gastrectomy with feeding jejunostomy was done. The histopathology revealed intestinal carcinoma, and regional lymph nodes involvement. The dissected specimen showed chronic gastritis with Helicobacter Pylori involvement (pT3 N2 C M1-G2-G3), and tumor free margins (Figure 1C).

\section{Discussion}

Krukenberg tumors tend to be in younger age groups with median age of 45 years $^{2}$. Most common presenting symptoms are abdominal pain, swelling in relation to the ovarian involvement, virilization, ascites, or pseudo-meigs syndrome ${ }^{3}$. Ultrasound is the best tool for screening the ovarian tumors, where as CT scan is essential for evaluation of extent of disease and adjacent visceral invasion. The imaging features of Krukenberg tumors will often suggest a malignant neoplasm but it will seldom be possible to differentiate them from other primary malignant ovarian neoplasms. type of poorly differentiated adeno- 
Frozen section diagnosis is a reliable method with good sensitivity and higher specificity for the surgical management of patients with an ovarian mass. Imunohistochemistry is helpful in distinguishing the primary and metastatic ovarian carcinoma. Thus pathological diagnosis forms an essential part in secondary ovarian tumors.

Optimal treatment strategies for metachronous Krukenberg's tumors, ovarian metastases of gastrointestinal tumors, have not been clearly established. Surgery has been suggested as an option, given that Krukenberg's tumors have been reported to be a sole metastatic lesion in some patients. Prognosis of the Krukenberg tumors is very poor, when compared to that of primary ovarian tumors. The estimated 5-year survival of this patient population was $12.1 \%$. Petru et $\mathrm{al}^{4}$ reviewed a series of 82 patients with nongenital cancers metastatic to the ovary and got a result that the overall actual 5-year survival rate was $10 \%$; all patients died within 58 months. Absence of metastases to viscera and lymph nodes and residual disease are favorable factors for metachronous tumors of gastric origin; not the age, size, stage of gastric adenocarcinoma after the ovarian metastasis ${ }^{5}$. The role of tumor free surgery and platinum based chemotherapy is reasonable to improve the overall prognosis of stage IV gastric cancer ${ }^{6,7}$.

Timing of operation for Krukenberg tumor may also influence survival. Whether the surgery should be performed synchronously or metachronously. In our case thorough preoperative evaluation was not done, as it was an emergency laparotomy. Hence both the primary and metastatic masses could not be removed at the same time.

Our patient has received total 6 cycles of chemotherapy until now. The first 2 cycles were cisplatin. Other 4 cycles were placitaxel with cisplatin was given every 3 weeks. She is with oncology follow up.

\section{Conclusions}

Krukenberg tumours should also be considered in the differential diagnosis of acute abdomen, though very rare. Our reporting of this case hopefully adds further understanding in the literature of this rare tumour.

\section{REFERENCES}

1. Habib A, Khatun S. Krukenberg tumor: report of two cases. Mymensingh Med J. 2012; 21 (2): 348-52.

2. Al-Agha Om Fau - Nicastri AD, Nicastri AD. An in-depth look at Krukenberg tumor: an overview, Arch Pathol Lab Med 2006, 130: 1725-30.

3. Sakpal Sv Fau - Babel N, Babel N Fau Pulinthanathu R, Pulinthanathu R Fau Denehy TR, Denehy Tr Fau - Chamberlain RS, Chamberlain RS. Krukenberg tumor: metastasis of Meckel's diverticular adenocarcinoma to ovaries, J Nippon Med Sch 2009, 76: 96-102.

4. Petru E, Pickel H, Heydarfadai M, Lahousen M, Haas J, Schaider H, Tamussino $\mathrm{K}$. Nongenital cancers metastatic to the ovary, Gynecol Oncol 1992, 44: 83-6.

5. Kim HK, Heo DS, Bang YJ, Kim NK. Prognostic factors of Krukenberg's tumor, Gynecol Oncol 2001, 82: 105-9.

6. Sandmeier D, Lobrinus JA, Vial Y, Delaloye JF, Genton CY. Bilateral Krukenberg tumor of the ovary during pregnancy, Eur $\mathrm{J}$ Gynaecol Oncol 2000, 21: 58-60.

7. Cosme A, Ojeda E, Bujanda L, Torrado J, Barrio J. [Krukenberg tumor secondary to gastric carcinoma in a woman in her eighth month of pregnancy], Gastroenterol Hepatol 2001; 24: 63-5. 